\title{
GSTMI and APEI genotypes affect arsenic-induced oxidative stress: a repeated measures study
}

\author{
Carrie V Breton*1,2, Molly L Kile ${ }^{1}$, Paul J Catalano ${ }^{3,4}$, Elaine Hoffman ${ }^{4}$, \\ Quazi Quamruzzaman' ${ }^{5}$, Mahmuder Rahman ${ }^{5}$, Golam Mahiuddin ${ }^{5}$ and \\ David C Christiani ${ }^{1}$
}

\begin{abstract}
Address: ${ }^{1}$ Harvard School of Public Health, Dept of Environmental Health, 665 Huntington Avenue, Boston, MA 02115, USA, ${ }^{2}$ University of Southern California, Keck School of Medicine, 1540 Alcazar Street, CHP 236 Los Angeles, CA 90033, USA, ${ }^{3}$ Dana-Farber Cancer Institute, 375 Longwood Avenue 2nd floor, Boston, MA 02115, USA, ${ }^{4}$ Harvard School of Public Health, Dept of Biostatistics, 655 Huntington Avenue, Boston, MA 02115, USA and ${ }^{5}$ Dhaka Community Hospital, 190/1 Baro Moghbazar, Wireless Railgate, 1217, Dhaka, Bangladesh

Email: Carrie V Breton* - breton@usc.edu; Molly L Kile - mkile@hsph.harvard.edu; Paul J Catalano - pcata@jimmy.harvard.edu; Elaine Hoffman - ehoffman@ @sph.harvard.edu; Quazi Quamruzzaman - dch@bangla.net; Mahmuder Rahman - dch@bangla.net; Golam Mahiuddin - dch@bangla.net; David C Christiani - dchris@hsph.harvard.edu

* Corresponding author
\end{abstract}

Published: 4 December 2007

Environmental Health 2007, 6:39 doi:10.1 186/1476-069X-6-39

This article is available from: http://www.ehjournal.net/content/6/1/39

(C) 2007 Breton et al; licensee BioMed Central Ltd.

This is an Open Access article distributed under the terms of the Creative Commons Attribution License (http://creativecommons.org/licenses/by/2.0), which permits unrestricted use, distribution, and reproduction in any medium, provided the original work is properly cited.

\begin{abstract}
Background: Chronic arsenic exposure is associated with an increased risk of skin, bladder and lung cancers. Generation of oxidative stress may contribute to arsenic carcinogenesis.

Methods: To investigate the association between arsenic exposure and oxidative stress, urinary 8hydroxy-2'-deoxyguanosine (8-OHdG) was evaluated in a cohort of 97 women recruited from an arsenicendemic region of Bangladesh in 2003. Arsenic exposure was measured in urine, toenails, and drinking water. Drinking water and urine samples were collected on three consecutive days. Susceptibility to oxidative stress was evaluated by genotyping relevant polymorphisms in glutathione-s transferase mu (GSTMI), human 8-oxoguanine glycosylase ( $h O G G l$ ) and apurinic/apyrimidinic endonuclease (APEI) genes using the Taqman method. Data were analyzed using random effects Tobit regression to account for repeated measures and $8-\mathrm{OHdG}$ values below the detection limit.
\end{abstract}

Results: A consistent negative effect for APEI was observed across water, toenail and urinary arsenic models. APEI $148 \mathrm{glu} / \mathrm{glu}+$ asp/glu genotype was associated with a decrease in logged 8-OHdG of 0.40 $(95 \% \mathrm{Cl}-0.73,-0.07)$ compared to APEI I 48 asplasp. An association between total urinary arsenic and 8OHdG was observed among women with the GSTMI null genotype but not in women with GSTMI positive. Among women with GSTMI null, a comparison of the second, third, and fourth quartiles of total urinary arsenic to the first quartile resulted in a 0.84 increase $(95 \% \mathrm{Cl} 0.27,1.42)$, a 0.98 increase $(95 \% \mathrm{Cl}$ $033, \mathrm{I} .66)$ and a 0.85 increase $(95 \% \mathrm{Cl} 0.27, \mathrm{I} .44)$ in logged $8-\mathrm{OHdG}$, respectively. No effects between 8 OHdG and toenail arsenic or drinking water arsenic were observed.

Conclusion: These results suggest the APEI variant genotype decreases repair of 8-OHdG and that arsenic exposure is associated with oxidative stress in women who lack a functional GSTM / detoxification enzyme. 


\section{Introduction}

Arsenic, a naturally occurring element, is a common environmental contaminant. Elevated concentrations can occur in drinking water, the primary route of exposure, through natural and anthropogenic process. Many countries are affected by arsenic-contaminated groundwater including Argentina, Australia, Chile, China, Hungary, India, Mexico, and the United States. However, the most affected region is Bangladesh, where an estimated 29 to 40 million people are at risk of ingesting arsenic-contaminated drinking water [1]. While epidemiological studies have clearly demonstrated arsenic as a human carcinogen, the mechanisms of toxicity remain largely unknown [2].

One hypothesized mechanism involves the induction of oxidative stress through the generation of reactive oxygen species (ROS) [3]. Animal and in vitro experiments have shown that arsenic induces oxidative stress in the liver, brain and blood of rats, increases oxidant levels in cultured aortic endothelial cells, increases intracellular peroxide levels, and reduces antioxidant levels [4-6]. Furthermore, mice that have been administered the arsenic metabolite dimethylarsinic acid (DMA V) orally and topically have developed skin tumors and shown increased levels of 8-hydroxyguanine in the epidermis [7].

Whether chronic arsenic exposure in humans causes oxidative stress is less certain. In a small cross-sectional study of Chinese community residents exposed to drinking water arsenic, oxidative stress levels, measured by mean serum levels of lipid peroxide, were significantly higher among the arsenic-exposed group [8]. Non-protein sulfhydrl groups such as glutathione in serum, which act as nucleophilic scavengers and protect against oxidative damage, were also inversely correlated with mean serum arsenic levels. In another study, blood arsenic levels correlated positively with the level of plasma oxidant species and inversely with plasma antioxidant capacity [9]. Several epidemiologic studies have also demonstrated an association between arsenic and the oxidative biomarker, 8-hydroxy-2'-deoxyguanosine (8-OHdG) [10,11]. In addition, skin tissue studies have shown significant differences in 8-OHdG concentration when comparing arsenic exposed and unexposed skin samples [12].

8-OHdG is a byproduct of ROS damage to DNA which can cause mutation of $\mathrm{G}: \mathrm{C}$ to $\mathrm{T}: \mathrm{A}$ if it remains in the DNA at the time of replication. $8-\mathrm{OHdG}$ in urine is a widely accepted marker of oxidative DNA damage and oxidative stress [13]. Normal DNA repair removes 8-OHdG adducts which are excreted and measurable in urine, blood and tissues. The urinary levels of oxidized products of nucleic acid breakdown thus reflect the amount of DNA damage incurred by ROS and repaired by the body's normal repair processes [14].
Numerous genes influence the generation and repair of oxidative lesions. Some of the most well-studied include genes in the base excision repair (BER) pathway and glutathione-s transferase (GSTs) [15]. Polymorphisms in these genes may affect the association between arsenic and 8-OHdG. Specifically, 8-OHdG lesions are repaired by human 8-oxoguanine glycosylase (hOGG1) in combination with apurinic/apyrimidinic endonuclease (APE1) [16]. Variants in the two genes hOGG1 Ser326Cys and the APE1 Asp148Glu have demonstrated a decreased ability to repair oxidative damage [17]. GSTs, a superfamily of multifunctional enzymes involved in cellular detoxification, conjugate and eliminate electrophilic carcinogens and scavenge free radicals [18]. A role for glutathione-s transferase mu (GSTM1) in DNA repair has also been suggested [19]. A homozygous deletion in the GSTM1 gene results in lack of enzyme and is generally hypothesized to increase the accumulation of cellular DNA damage [20]. GSTs have also been associated with an increased risk for oxidative stress-related diseases. For example, GSTM1 null genotype was associated with cutaneous basal cell carcinoma and with solar keratoses $[19,21]$.

Studies have demonstrated that the magnitude of disease risk is greater when the GSTM1 null genotype interacts with other factors [20]. Because homozygous deletions in GSTM1 have been associated with changes in arsenic methylation capability [22], GSTM1 genotype may alter arsenic toxicity and therefore modify the association between arsenic and urinary 8-OHdG.

In the present study, we investigated whether chronic arsenic exposure was associated with oxidative stress by evaluating the association between total urinary arsenic (TUA), toenail arsenic and drinking water arsenic and urinary 8-OHdG concentration among a cohort of Bangladeshi women who did not exhibit any cutaneous signs of arsenic toxicity and were exposed to a wide range of arsenic concentrations in drinking water. In addition, we evaluated effect modification of several genotypes including hOGG1 Ser326Cys, APE1 Asp148Glu, and GSTM1 null.

\section{Methods \\ Participant Selection}

Participants were recruited through a series of community meetings held in three villages in Pabna, Bangladesh that are serviced by the Pabna Community Clinic. Overall, 248 individuals from 50 households were recruited to participate in a repeated measures study to characterize biomarker response. Details regarding the full cohort are described elsewhere [23]. Briefly, subjects were eligible for this study if they were long-term residents of Pabna, obtained their drinking water from tube wells, and received primary health care from the Pabna Community Clinic, an affiliate of Dhaka Community Hospital (DCH). 
During the initial visit, a behavioral and demographic questionnaire was administered and a blood sample collected. Researchers visited participants at their homes every three months to collect urine, toenail, and water samples.

For this study, the cohort was restricted to women who provided urine samples from April 15, 2003 to June 27, 2003. The cohort was restricted to women because they spent more time at home and thus may have a more consistent exposure profile. These restrictions yielded 97 women and 290 urine samples for analysis. All women provided three consecutive days of urine samples except one, who only provided two samples.

Institutional Review Boards at the Harvard School of Public Health and DCH approved the protocol for this study. Informed consent was obtained prior to participation.

\section{Arsenic measurement}

First void urine samples were collected from participants and stored at $-20^{\circ} \mathrm{C}$ until analysis. Multiple collections were used to reduce the effect of day-to-day variations in background levels of 8-OHdG. TUA was measured using high performance liquid chromatography-atomic absorption spectrophotometry (HPLC-HGAAS; HPLC model Waters 501, Waters Associates, Milford, MA, USA) as described by Hsueh et al [24]. This method quantifies arsenate (As V), arsenite (As III), monomethylarsonic acid (MMA), and dimethylarsenic acid (DMA). TUA was defined as the sum of As III, As V, MMA, and DMA. Detection limits for As III, As V, MMA, and DMA were 0.036, $0.055,0.054$, and $0.056 \mu \mathrm{g} / \mathrm{L}$, respectively.

Drinking water concentrations from family tube wells were measured on each day of urine collection. Water samples were collected in acid-washed polyethylene containers and preserved with Reagent Grade $\mathrm{HNO}_{3}$ (Merck, Germany) to a $\mathrm{pH}<2$. Total inorganic arsenic analysis was performed by Environmental Laboratory Services (North Syracuse, New York) following U.S. Environmental Protection Agency method 200.8. The limit of detection for this method is $1 \mu \mathrm{g}$ As/l. Measurements that fell below the limit of detection were assigned a value of half the limit of detection for statistical analyses. PlasmaCAL multi-element QC standard \#1 solution (SCP Science, Canada) was used to validate analysis.

Toenail clippings were collected from all toes and prepared as described by Chen et al [25]. Arsenic was analyzed using an inductively-coupled plasma mass spectrometer (ICP-MS Model 6100 DRC, Perkin-Elmer, Norwalk, CT). Standard reference material water (NIST 1643d Trace Elements in Water; National Institute of Standards and Technology, Gaithersburg, MD) and certi- fied human hair reference material (CRM Hair; Shanghai Institute of Nuclear Research, Academia Sinica, China) were used to validate instrument performance and digestion method. The average percent recovery of NIST 1643 and CRM hair was $92.4 \%$ and $94.5 \%$, respectively.

The reported inorganic arsenic concentrations were corrected for any detectable blank concentrations and for systemic error by normalizing the sample concentrations against the measured average daily NIST 1643 inorganic arsenic concentration [23]. This corrected value was used in all the statistical analyses.

\section{8-OHdG measurement}

One milliliter of urine was shipped overnight on dry ice to Genox Laboratories (Baltimore, MD) for analysis. 8OHdG was measured using an ELISA assay, a competitive immunoassay in which color intensity is inversely proportional to the concentration of 8-OHdG in the urine samples [26]. A pooled urine sample from several healthy adults was used as the in-house quality control. Triplicate measurements were performed on all samples, their values averaged, and any sample with a percent coefficient of variation $(\mathrm{SD} /$ mean expressed as a percentage; \%CV) equal or greater than $20 \%$ was re-tested. The limit of detection for this method was $0.64 \mu \mathrm{g} / \mathrm{l}$. Several methods are available for measurement of $8-\mathrm{OHdG}$, including ELISA, HPLC-ECD, LC/MS/MS and GC/MS. Although some evidence suggests the ELISA may be less sensitive and overestimate values compared to other methods, it is a readily available and easy assay which has demonstrated good correlation between 8 -OHdG values measured by both HPLC-ECD and LC/MS/MS [27].

\section{Creatinine measurement}

Creatinine was measured using the Sigma Diagnostics creatinine assay (Genox Laboratories) from the same sample used for 8-OHdG analysis. This assay measures creatinine by a kinetic modification of the Jaffe reaction [28].

\section{Genotyping}

Multiplex polymerase chain reaction amplifications were performed from genomic DNA extracted from whole blood following the Puregene Protocol (Gentra Systems, Minnesota). Genotyping of the GSTM1deletion followed the protocol described by Liu et al [29]. The following primers were used: 5'-CGCCATCTTGTGCTACATTGCCCG-3' and 5'-TCTGGATTGTAGCAGATCA-3'. The hOGG1 Ser326Cys (rs1052133) and APE1 Asp148Glu (rs3136820) polymorphisms were detected by the Taqman method using the ABI Prism 7900HT Sequence Detection System (Applied Biosystems, Foster City, CA). Primers for hOGG1 and APE1 were as follows: a) 5'-ACAGACTCCACCCTCCTACAG-3', b) 5'-ACССТTTCTGCGCTTTGCT-3', c) 
GATTGCTTTCCCTTTTCTTATAGTTTTTTATGCT-3', and d) 5'-CACCCGGCCTTCCTGAT-3', respectively. Genotyping procedures were validated by randomly selecting $5 \%$ of the samples and subjecting them to repeat analysis. Two researchers independently reviewed all genotyping results and samples with unclear results were rerun until 100\% concordance was achieved.

\section{Statistical analysis}

All analyses were conducted using Tobit regression (STATA, version 9.2, College Station, TX). This method was chosen because of its ability to validly account for leftcensored data since $25 \%$ of $8-\mathrm{OHdG}$ values in our dataset were below the limit of detection [30]. Models included a random effect to account for the correlation between repeated urine measures. Arsenic, $8-\mathrm{OHdG}$ and creatinine concentrations were strongly right skewed but appeared to be lognormal when transformed using a natural logarithm. TUA, toenail arsenic and drinking water arsenic concentrations were initially treated as continuous variables in all models, then categorized into quartiles to evaluate potential non-linear associations. Estimated betas and their corresponding 95\% confidence intervals were computed for the parameters of interest according to the following model:

$\ln \left(8-\mathrm{OHdG}_{\mathrm{ij}}\right)=\alpha_{\mathrm{ij}}+\beta_{A s} \ln \mathrm{As}_{\mathrm{ij}}+\beta_{\mathrm{G}} \mathrm{Gene}_{\mathrm{ij}}+\beta_{\mathrm{Z}} \mathrm{Z}_{\mathrm{ij}}+\mathrm{b}_{\mathrm{j}}{ }_{\mathrm{ij}}^{(2)}+$

where $\alpha_{i j}$ is a baseline intercept for the $i^{\text {th }}$ observation in the $j^{\text {th }}$ woman; $A s_{i j}$ is arsenic in drinking water, toenails, or urine; Gene $_{\mathrm{ij}}$ is a main effect for GSTM1, APE1 or hOGG1 genotype; $Z_{i j}$ is a vector of covariates; $b_{j}{ }^{(2)}$ is a random person effect; and the $\beta$ coefficients are the parameters to be estimated.

All models were adjusted for potential confounding by age, BMI, education, creatinine, betel nut chewing and the presence of at least one smoker in the household. Chewing tobacco, drinking tea, childhood tan level and childhood skin reaction to approximately two hours of sun exposure were initially evaluated for potential confounding but then dropped from subsequent models because none of these variables appreciably changed the effect estimates for arsenic. None of the women reported smoking cigarettes themselves so confounding by smoking was not relevant.

Lastly, effect modification of the association between arsenic and 8-OHdG by polymorphisms in GSTM1, APE1, and $h O G G 1$ was evaluated by including interaction terms in the model above. Heterozygous and homozygous variant genotypes were combined and compared to their corresponding common variants for all genes. Stratumspecific effect estimates and confidence intervals were cal- culated directly from models that included interaction terms. For the models in which arsenic was categorized into quartiles, Wald p-values were presented for specific quartile-gene interactions and likelihood ratio tests were performed to test whether the group of arsenic variables and the group of gene-arsenic interactions as a whole were associated with 8-OHdG levels.

\section{Results}

Sociodemographic information for the 97 Bangladeshi women who provided 290 urine samples included in this analysis are provided in Table 1 . The majority of women were married $(82.5 \%)$ and had only a primary education level or lower $(71.2 \%)$. None of the women reported smoking, although 51.6\% reported having at least one smoker in the household and 28.9\% reported chewing betel nuts. Prevalence of the variant genotypes was $4.2 \%$ for APE1 glu/glu, $13.8 \%$ for hOGG1 cys/cys, and $27.8 \%$ for GSTM1 null. The median value of TUA was $22.6(\mu \mathrm{g} /$ $1)$, though a wide range $(1.35-431.3 \mu \mathrm{g} / \mathrm{l})$ was observed (Table 2). When urinary 8-OHdG samples were analyzed, $25 \%$ were below the limit of detection. The median $8-$ OHdG value was $3.25 \mu \mathrm{g} / \mathrm{l}$ (range 0.64 - $82.6 \mu \mathrm{g} / \mathrm{l}$ ). 8 OHdG measurements from each woman exhibited a fair degree of variability. The average $\% \mathrm{CV}$ was $55.1 \%$ with a range from 4.0 to $152.8 \%$. The adjusted within-person correlation for daily measurements, calculated directly from the Tobit model in Table 3, was 0.47 .

Table I: Sociodemographic and genetic characteristics of 97 women from Pabna, Bangladesh

\begin{tabular}{|c|c|c|}
\hline & $\%$ & $\mathbf{N}$ \\
\hline \multicolumn{3}{|l|}{ Marital status } \\
\hline Married & 82.5 & 80 \\
\hline Married & 8.3 & 8 \\
\hline Widowed & 9.3 & 9 \\
\hline \multicolumn{3}{|l|}{ Education } \\
\hline Illiterate & 15.5 & 15 \\
\hline Able to write & 39.2 & 38 \\
\hline Primary & 16.5 & 16 \\
\hline Secondary & 17.5 & 17 \\
\hline Higher 2nd & 9.3 & 9 \\
\hline College/graduate & 2.1 & 2 \\
\hline Smokers in the household & 51.6 & 50 \\
\hline Chew betel nuts & 28.9 & 28 \\
\hline \multicolumn{3}{|l|}{ hOGGI Ser326Cys } \\
\hline Cys/cys & 13.8 & 13 \\
\hline Cys/ser & 44.7 & 42 \\
\hline Ser/ser & 41.5 & 39 \\
\hline \multicolumn{3}{|l|}{ APEI Asp / 48Glu } \\
\hline Glu/glu & 4.2 & 4 \\
\hline Asp/glu & 32.6 & 31 \\
\hline Asp/asp & 63.2 & 60 \\
\hline \multicolumn{3}{|l|}{ GSTMI } \\
\hline Null & 27.8 & 27 \\
\hline Positive & 72.2 & 70 \\
\hline
\end{tabular}


Table 2: Exposure distributions and physical characteristics of 97 women from Pabna, Bangladesh

\begin{tabular}{|c|c|c|c|c|}
\hline & mean & SD & median & range \\
\hline \multicolumn{5}{|l|}{ urinary measures } \\
\hline Total urinary arsenic $(\mu \mathrm{g} / \mathrm{l})^{\dagger}$ & 39.5 & 53.1 & 22.6 & $1.35-431.3$ \\
\hline 8-OHdG $(\mu \mathrm{g} / \mathrm{l})^{* \dagger}$ & 6.1 & 9.0 & 3.3 & $0.64-82.6$ \\
\hline Creatinine $(\mathrm{mg} / \mathrm{dl})^{\dagger}$ & 48.3 & 33.9 & 39.4 & $4.3-230.5$ \\
\hline \multicolumn{5}{|l|}{ toenail measure } \\
\hline Toenail arsenic $(\mu g / g)$ & 1.4 & 1.5 & 0.8 & $0.22-10.16$ \\
\hline \multicolumn{5}{|l|}{ drinking water measure } \\
\hline Water arsenic $(\mu \mathrm{g} / \mathrm{l})$ & 64.7 & 115.9 & 1.46 & $0.5-591$ \\
\hline \multicolumn{5}{|l|}{ physical characteristics } \\
\hline Age & 34.8 & 12.9 & 33.0 & $17-70$ \\
\hline BMI & 21.3 & 3.6 & 21.4 & $12.9-30.3$ \\
\hline
\end{tabular}

$* 25 \%$ of $8-O H d G$ values were below the LOD.

trepeated measurements for each woman were included separately for a total of 290 values

Arsenic variables were log-transformed and treated as continuous variables and also categorized into quartiles to evaluate non-linear associations. In models adjusting for potential confounders, no associations between 8 -OHdG and any of the arsenic variables were observed regardless of how the variables were parameterized (Table 3). A consistent negative main effect for APE1 genotype was observed across water, toenail and urinary arsenic models, although it was only statistically significant for toenail arsenic (Table 3). For example, in the model evaluating toenail arsenic concentration, APE1 $148 \mathrm{glu} / \mathrm{glu}+\mathrm{asp} / \mathrm{glu}$ genotype was associated with a decrease in logged 8OHdG of 0.40 (95\%CI -0.73, -0.07) compared to APE1 148 asp/asp. Creatinine, betel nut chewing, presence of environmental tobacco smoke in the home, and education were also predictive of 8-OHdG levels.
Interactions between genotypes and 8-OHdG were assessed and an interaction observed for GSTM1, but not for APE1 or hOGG1. TUA was positively associated with 8OHdG in women with the GSTM1 null genotype, but not in women with GSTM1 positive (Table 4). Among women with GSTM1 null, a comparison of the second, third, and fourth quartiles of TUA to the first quartile resulted in a 0.84 increase $(95 \%$ CI $0.27,1.42)$, a 0.98 increase (95\% CI $0.33,1.66)$ and a 0.85 increase $(95 \%$ CI $0.27,1.44)$ in logged $8-\mathrm{OHdG}$, respectively. These results suggest a plateau effect for arsenic on 8-OHdG. A likelihood ratio test evaluating the significance of the GSTM1 interaction terms as a group yielded a p-value of 0.007 . A model in which TUA was dichotomized at the median yielded similar results (data not shown). The same interaction was not evident in models which used toenail or drinking water arsenic instead of TUA.

\section{Discussion}

This study observed a positive association between total urinary arsenic and $8-\mathrm{OHdG}$, a biomarker of oxidative stress, among healthy women possessing the GSTM1 null genotype but not among women with the GSTM1 positive genotype. In addition, a negative main effect for APE1 genotype was observed. The APE1 variant allele was associated with a decrease in $8-\mathrm{OHdG}$ which is consistent with observations that polymorphisms in the APE1 gene confer a decreased ability to repair oxidative damage [17].

Several epidemiologic studies have demonstrated an association between arsenic exposure and 8-OHdG $[10,11]$. Arsenic-related skin tumors taken from individuals currently living in arsenic-endemic areas also showed differ-

Table 3: Main effects* of arsenic and covariates on logged urinary 8-OHdG $(\mu \mathrm{g} / \mathrm{I})(\mathbf{N}=290)$

\begin{tabular}{|c|c|c|c|c|c|c|}
\hline \multirow[b]{2}{*}{ Variable } & \multicolumn{2}{|c|}{ Urine } & \multicolumn{2}{|c|}{ Drinking water } & \multicolumn{2}{|c|}{ Toenail } \\
\hline & $\beta$ & $95 \% \mathrm{Cl}$ & $\beta$ & $95 \% \mathrm{Cl}$ & $\beta$ & $95 \% \mathrm{Cl}$ \\
\hline \multicolumn{7}{|l|}{ Arsenic quartile } \\
\hline Ist & reference & & reference & & reference & \\
\hline 2nd & 0.16 & $(-0.15,0.46)$ & 0.02 & $(-0.30,0.34)$ & -0.16 & $(-0.63,0.304)$ \\
\hline $3 r d$ & 0.22 & $(-0.12,0.55)$ & 0.22 & $(-0.11,0.55)$ & -0.32 & $(-0.773,0.13)$ \\
\hline 4th & 0.17 & $(-0.21,0.56)$ & -0.16 & $(-0.55,0.23)$ & -0.33 & $(-0.78,0.12)$ \\
\hline Logged creatinine & 2.18 & $(1.96,2.40)$ & 2.23 & $(2.05,2.42)$ & 2.24 & $(2.06,2.42)$ \\
\hline BMI & -0.01 & $(-0.06,0.03)$ & -0.01 & $(-0.05,0.03)$ & -0.01 & $(-0.05,0.03)$ \\
\hline Age & 0.01 & $(0.00,0.03)$ & 0.02 & $(0.00,0.03)$ & 0.01 & $(0.00,0.02)$ \\
\hline Chews betelnuts & -0.40 & $(-0.78,-0.03)$ & -0.46 & $(-0.84,-0.09)$ & -0.41 & $(-0.78,-0.04)$ \\
\hline ETSt in the home & -0.47 & $(-0.79,-0.16)$ & -0.36 & $(-0.69,-0.03)$ & -0.43 & $(-0.75,-0.10)$ \\
\hline Educationt† & -0.72 & $(-1.10,-0.34)$ & -0.70 & $(-1.08,-0.32)$ & -0.72 & $(-1.11,-0.33)$ \\
\hline GSTMI & -0.02 & $(-0.37,0.33)$ & 0.06 & $(-0.30,0.4 I)$ & -0.01 & $(-0.36,0.34)$ \\
\hline hOGGI & -0.03 & $(-0.34,0.28)$ & -0.01 & $(-0.32,0.29)$ & -0.06 & $(-0.37,0.24)$ \\
\hline APEI & -0.28 & $(-0.60,0.04)$ & -0.28 & $(-0.59,0.03)$ & -0.40 & $(-0.73,-0.07)$ \\
\hline
\end{tabular}

* Main effects are from three random effects Tobit models.

tETS is environmental tobacco smoke.

t†Education compared secondary or higher to primary or less 
Table 4: The effect of quartiles of arsenic on logged urinary 8-OHdG $(\mu \mathrm{g} / \mathrm{I})$ by GSTMI genotype $(\mathrm{N}=290)$

\begin{tabular}{|c|c|c|c|c|c|c|}
\hline \multirow[b]{2}{*}{ Model* } & \multicolumn{2}{|c|}{ GSTMI positive } & \multicolumn{2}{|c|}{ GSTMI null } & \multirow[t]{2}{*}{ Wald p-value ${ }^{\dagger}$} & \multirow[t]{2}{*}{ LRT p-valuett } \\
\hline & $\beta$ & $95 \% \mathrm{Cl}$ & $\beta$ & $95 \% \mathrm{Cl}$ & & \\
\hline Total urinary arsenic quartile $(\mu g / l)$ & & & & & & 0.007 \\
\hline $1.35-13.3$ & reference & & reference & & & \\
\hline$>13.3-22.6$ & -0.12 & $(-0.46,0.22)$ & 0.84 & $(0.27,1.42)$ & 0.004 & \\
\hline$>22.6-47.9$ & -0.06 & $(-0.43,0.31)$ & 0.98 & $(0.33,1.66)$ & 0.005 & \\
\hline$>47.9-431.3$ & -0.15 & $(-0.60,0.30)$ & 0.85 & $(0.27,1.44)$ & 0.004 & \\
\hline Drinking water arsenic quartile $(\mu \mathrm{g} / \mathrm{l})$ & & & & & & 0.69 \\
\hline 0.5 & reference & & reference & & & \\
\hline$>0.50-1.5$ & -0.05 & $(-0.42,0.31)$ & 0.26 & $(-0.4 I, 0.93)$ & 0.43 & \\
\hline$>1.5-81.7$ & 0.29 & $(-0.11,0.69)$ & 0.15 & $(-0.46,0.75)$ & 0.69 & \\
\hline$>81.7-591$ & -0.21 & $(-0.66,0.24)$ & 0.002 & $(-0.74,0.75)$ & 0.63 & \\
\hline Toenail arsenic quartile $(\mu g / g)$ & & & & & & 0.69 \\
\hline $0.2-0.6$ & reference & & reference & & & \\
\hline$>0.6-0.8$ & -0.19 & $(-0.7 I, 0.33)$ & -0.09 & $(-0.93,0.75)$ & 0.83 & \\
\hline$>0.8-1.6$ & -0.36 & $(-0.87,0.14)$ & -0.22 & $(-1.06,0.63)$ & 0.77 & \\
\hline$>1.6-10.2$ & -0.49 & $(-1.00,0.03)$ & 0.05 & $(-0.76,0.87)$ & 0.26 & \\
\hline
\end{tabular}

*Main effects are from three random effects Tobit models adjusted for logged creatinine, BMI, age, betelnut chewing, environmental tobacco smoke, and education (secondary or higher vs primary or less), and hOGGI and APEI genotypes.

† significance test for individual interaction terms.

tt significance test for the entire group of arsenic quartile by gene interactions

ences in 8-OHdG concentration compared to tumors from unexposed individuals [12]. Similarly, exposure of human keratinocytes to arsenite caused formation of superoxide anion, hydrogen peroxide, and 8-OHdG in a concentration- and time-dependent manner [31].

The positive association between arsenic exposure and 8OHdG in GSTM1 null individuals provides evidence that there may be genetically susceptible subpopulations. GSTM1 mediates the generation of oxidative stress [32], can scavenge free radicals [18], and can also affect arsenic metabolism [22]. Women with the null genotype excreted a significantly higher proportion of arsenic as MMA than women with the positive genotype [33]. Increased percentage of MMA has been associated with increased risk of several arsenic-related diseases [34]. Therefore, lack of a functional GSTM1 enzyme may alter arsenic metabolism in favor of production of 8-OHdG.

Further evidence exists for interactions involving GSTM1 and oxidative stress for other environmental exposures. Bikers exposed to high ozone levels and smokers have shown positive associations with 8-OHdG DNA adduct levels only among individuals with the GSTM1 null genotype $[35,36]$. Individuals with GSTM1 null genotype also have an increased cancer risk for skin type I and basal cell carcinoma [19] and for smoking and lung cancer [20].

In this study, a positive association was observed only when TUA was used as the exposure metric and not for drinking water arsenic and toenail arsenic. This discrepancy may reflect differences in exposure misclassification.
Toenail arsenic reflects an accumulation of historical arsenic exposure over relatively long periods of time [23]. Thus, arsenic deposited in the toenail 3-9 months prior to urinary 8-OHdG collection may not reflect the exposure relevant for urinary 8-OHdG excretion. Similarly, drinking water arsenic measurements represent a single point source of arsenic use but may not reflect total arsenic dose in the body from all routes of exposure. However, TUA measured in the same urine sample as 8 -OHdG reflects recent arsenic exposure at a point in time much more relevant to the generation of the measured $8-\mathrm{OHdG}$, making it a more appropriate biomarker of exposure.

There did not appear to be a linear dose response relationship between 8-OHdG and TUA. Instead, 8-OHdG seemed to plateau at relatively low levels of urinary arsenic. However, this is a highly exposed population and it is possible that the range of arsenic exposures was insufficient to capture a linear dose response between urinary arsenic and urinary 8-OHdG before repair pathways became saturated. It is also possible that the high arsenic exposure led to an up-regulation in oxidative stress repair. Either explanation would account for the observed plateau in urinary 8-OHdG. Furthermore, it is also plausible that in the absence of GSTM1 enzyme alternate pathways repair oxidative damage generated from arsenic exposure.

Several limitations to the present study are worth mentioning. The sample size was relatively small, and yet the study was sufficiently powered to detect an interaction between 8-OHdG level and GSTM1 genotype. The failure to detect an association among women with GSTM1 pos- 
itive genotype was not due to insufficient statistical power since this group of women was the larger stratum. Rather, it suggested that exposure to arsenic was required to reveal a different oxidative stress response between women who had the GSTM1 positive genotype that codes for the production of glutathione s-transferase mu and women who had the GSTM1 null genotype and cannot produce glutathione s-transferase mu.

Also, urinary 8-OHdG reflects oxidative DNA damage that occurs throughout the body that is corrected by DNA repair mechanisms before being excreted in urine. Thus, the effects observed in this study may reflect changes in generation of oxidative damage or changes in repair of oxidative damage or some combination of both. Furthermore, urinary 8-OHdG is a stable biomarker that is easy to measure [37] but it is not a very specific biomarker. 8OHdG exhibits a large degree of intra-individual variability indicating a large endogenous variation of oxidative DNA damage $[37,38]$. In our study, the average $\% \mathrm{CV}$ was $55.1 \%$ with a range from 4.0 to $152.8 \%$, which was consistent with previously published work $[37,38]$. By using three urine samples collected on consecutive days for each woman, we were able to reduce individual variability and estimate a more precise value of an individual's base level of 8-OHdG.

In all models, creatinine was significantly associated with 8-OHdG. Creatinine is often used to adjust urinary markers for variations in urine volume or dilution by dividing the biomarker value by the creatinine value [37]. Instead, we adjusted for creatinine by including it as a log-transformed independent predictor in accordance with recent studies suggesting this is a better modeling technique, particularly when evaluating chemicals involved in one-carbon metabolism [39].

We also cannot rule out the possibility of residual confounding by sun exposure. UV exposure is a potent oxidant that can generate DNA damage that needs to be repaired. It has been implicated as a co-carcinogen with arsenic on the development of skin lesions [40]. We attempted to control for measures of sun exposure by evaluating two variables in our dataset: childhood tan level and childhood skin reaction to two hours of sun exposure. Neither of these variables appreciably changed our results; however, these variables provided only crude measurements of skin type.

\section{Conclusion}

We observed a novel interaction between arsenic and GSTM1 genotype in association with urinary 8-OHdG in a population of healthy women. Urinary 8-OHdG concentration increased in response to increasing quartiles of total urinary arsenic only among women with the GSTM1 null genotype. These results suggest individuals that lack a functional GSTM1 enzyme can not detoxify arsenic well, resulting in an increase in oxidative stress. In addition, APE1 148Glu allele was associated with a decrease in 8OHdG, suggesting the polymorphism affects repair of this adduct. These results contribute to a growing body of evidence that arsenic is associated with oxidative stress and repair of oxidative damage. The data also suggest it is increasingly important to consider genetically susceptible populations, as variation in genetic pathways involved in oxidative stress and arsenic toxicity may explain some of the heterogeneity in research results across studies.

\section{Abbreviations}

8-OHdG: Urinary 8-hydroxy-2'-deoxyguanosine;

ROS: reactive oxygen species;

DMA V: Dimethylarsinic acid;

GSTs: Glutathione-s transferase;

hOGG1: Human 8-oxoguanine glycosylase;

APE1: Apurinic/apyrimidinic endonuclease;

TUA: Total urinary arsenic;

DCH: Dhaka Community Hospital;

HPLC-HGAAS: High performance liquid chromatography-atomic absorption spectrophotometry;

As V: Arsenate;

As III: Arsenite;

MMA: Monomethylarsonic acid;

DMA: Dimethylarsenic acid;

ICP-MS: Inductively-coupled plasma mass spectrometer.

\section{Competing interests}

Dr. Christiani was a paid scientific advisor for Gentra Systems. The authors have no association with Genox or Environmental Laboratory Services other than as a purchaser of services for analysis of samples.

\section{Authors' contributions}

CB performed statistical analyses and drafted the paper. MK participated in arsenic measurement, sample quality control, and manuscript revision. PC and EH provided statistical and analytic help and guidance. QQ and MR participated in the study design and coordination of 
remote field operations in Bangladesh. GM organized data collection procedures, managed daily operations of field team, and processed biological samples. DC conceived of the study, participated in its design and coordination, and helped to draft the manuscript. All authors read and approved the final manuscript.

\section{Acknowledgements}

The authors thank our colleagues, technicians, laboratory, and administrative staff at Dhaka Community Hospital and the Pabna Community Clinic in Bangladesh as well as services provided by Genox and Environmental Laborotory Services. We also acknowledge the academic assistance of Tom Smith and the technical expertise of Janna Frelich, Lia Shimada, Li Su, Meredith Jones, and Chrissy Dobson.

This publication was made possible by NIH grants T32 ES07069, ESOI I 622, ES05947, and ES00002. Its contents are solely the responsibility of the authors and do not necessarily represent the official views of the $\mathrm{NIH}$.

\section{References}

I. Alam MG, Allinson G, Stagnitti F, Tanaka A, Westbrooke M: Arsenic contamination in Bangladesh groundwater: a major environmental and social disaster. Int J Environ Health Res 2002, 1 2:235-253.

2. Huang $C$, Ke $Q$, Costa M, Shi X: Molecular mechanisms of arsenic carcinogenesis. Mol Cell Biochem 2004, 255:57-66.

3. Shi $\mathrm{H}$, Shi $\mathrm{X}$, Liu KJ: Oxidative mechanism of arsenic toxicity and carcinogenesis. Mol Cell Biochem 2004, 255:67-78.

4. Flora SJ: Arsenic-induced oxidative stress and its reversibility following combined administration of $\mathbf{N}$-acetylcysteine and meso 2,3-dimercaptosuccinic acid in rats. Clin Exp Pharmacol Physiol 1999, 26:865-869.

5. Barchowsky A, Dudek EJ, Treadwell MD, Wetterhahn KE: Arsenic induces oxidant stress and NF-kappa B activation in cultured aortic endothelial cells. Free Radic Biol Med 1996, 2 1:783-790.

6. Ramos O, Carrizales L, Yanez L, Mejia J, Batres L, Ortiz D, Diaz-Barriga F: Arsenic increased lipid peroxidation in rat tissues by a mechanism independent of glutathione levels. Environ Health Perspect 1995, 103:85-88.

7. Mizoi M, Takabayashi F, Nakano M, An Y, Sagesaka Y, Kato K, Okada $\mathrm{S}$, Yamanaka $\mathrm{K}$ : The role of trivalent dimethylated arsenic in dimethylarsinic acid-promoted skin and lung tumorigenesis in mice: tumor-promoting action through the induction of oxidative stress. Toxicol Lett 2005, 1 58:87-94.

8. Pi J, Yamauchi H, Kumagai Y, Sun G, Yoshida T, Aikawa H, Hopenhayn-Rich $C$, Shimojo N: Evidence for induction of oxidative stress caused by chronic exposure of Chinese residents to arsenic contained in drinking water. Environ Health Perspect 2002, I 1 0:331-336.

9. Wu MM, Chiou HY, Wang TW, Hsueh YM, Wang IH, Chen CJ, Lee TC: Association of blood arsenic levels with increased reactive oxidants and decreased antioxidant capacity in a human population of northeastern Taiwan. Environ Health Perspect 200I, 109:101I-1017.

10. Fujino Y, Guo X, Liu J, Matthews IP, Shirane K, Wu K, Kasai H, Miyatake M, Tanabe K, Kusuda T, Yoshimura T: Chronic arsenic exposure and urinary 8-Hydroxy-2'-deoxyguanosine in an arsenicaffected area in Inner Mongolia, China. J Expo Anal Environ Epidemiol 2004, I5(2): 147-I52.

II. Hu CW, Pan CH, Huang YL, Wu MT, Chang LW, Wang CJ, Chao MR: Effects of arsenic exposure among semiconductor workers: a cautionary note on urinary 8-oxo-7,8-dihydro-2'-deoxyguanosine. Free Radic Biol Med 2006, 40:1273-1278.

12. An Y, Gao Z, Wang Z, Yang S, Liang J, Feng Y, Kato K, Nakano M, Okada S, Yamanaka K: Immunohistochemical analysis of oxidative DNA damage in arsenic-related human skin samples from arsenic-contaminated area of China. Cancer Lett 2004 214: $11-18$

13. Shibutani S, Takeshita M, Grollman AP: Insertion of specific bases during DNA synthesis past the oxidation-damaged base 8 oxodG. Nature 1991, 349:431-434.
14. Collins AR, Duthie SJ, Fillion L, Gedik CM, Vaughan N, Wood SG: Oxidative DNA damage in human cells: the influence of antioxidants and DNA repair. Biochem Soc Trans 1997, 25:326-33I.

15. Cooke MS, Evans MD, Dove R, Rozalski R, Gackowski D, Siomek A Lunec J, Olinski R: DNA repair is responsible for the presence of oxidatively damaged DNA lesions in urine. Mutat Res 2005, 574:58-66.

16. Lunec J, Holloway KA, Cooke MS, Faux S, Griffiths HR, Evans MD: Urinary 8-oxo-2'-deoxyguanosine: redox regulation of DNA repair in vivo? Free Radic Biol Med 2002, 33:875-885.

17. Vodicka P, Stetina R, Polakova V, Tulupova E, Naccarati A, Vodickova L, Kumar R, Hanova M, Pardini B, Slyskova J, Musak L, De Palma G, Soucek P, Hemminki K: Association of DNA repair polymorphisms with DNA repair functional outcomes in healthy human subjects. Carcinogenesis 2006, 28:657-664.

18. Parl FF: Glutathione S-transferase genotypes and cancer risk. Cancer Lett 2005, 22 1: I 23-129.

19. Lear JT, Smith AG, Strange RC, Fryer AA: Detoxifying enzyme genotypes and susceptibility to cutaneous malignancy. $\mathrm{Br} J$ Dermatol 2000, I 42:8-I5.

20. Rebbeck TR: Molecular epidemiology of the human glutathione S-transferase genotypes GSTMI and GSTTI in cancer susceptibility. Cancer Epidemiol Biomarkers Prev 1997, 6:733-743.

21. Carless MA, Lea RA, Curran JE, Appleyard B, Gaffney P, Green A, Griffiths LR: The GSTMI null genotype confers an increased risk for solar keratosis development in an Australian Caucasian population. J Invest Dermatol 2002, I I 9:1373-1378.

22. Chiou HY, Hsueh YM, Hsieh LL, Hsu LI, Hsu YH, Hsieh FI, Wei ML, Chen HC, Yang HT, Leu LC, Chu TH, Chen-Wu C, Yang MH, Chen $\mathrm{CJ}$ : Arsenic methylation capacity, body retention, and null genotypes of glutathione S-transferase $\mathrm{MI}$ and $\mathrm{TI}$ among current arsenic-exposed residents in Taiwan. Mutat Res 1997, 386: 197-207

23. Kile ML, Houseman EA, Rodrigues E, Smith TJ, Quamruzzaman $\mathrm{Q}$, Rahman M, Mahiuddin G, Su L, Christiani DC: Toenail arsenic concentrations, GSTT I gene polymorphisms, and arsenic exposure from drinking water. Cancer Epidemiology Biomarkers \& Prevention 2005, 14:2419-2426.

24. Hsueh YM, Huang YL, Huang CC, Wu WL, Chen HM, Yang MH, Lue LC, Chen CJ: Urinary levels of inorganic and organic arsenic metabolites among residents in an arseniasis-hyperendemic area in Taiwan. J Toxicol Environ Health A 1998, 54:43 I-444.

25. Chen KL, Amarasiriwardena C], Christiani DC: Determination of total arsenic concentrations in nails by inductively coupled plasma mass spectrometry. Biol Trace Elem Res 1999, 67:109-125.

26. Toyokuni S, Tanaka T, Hattori Y, Nishiyama $Y$, Yoshida A, Uchida $K$, Hiai $\mathrm{H}$, Ochi $\mathrm{H}$, Osawa T: Quantitative immunohistochemical determination of 8-hydroxy-2'-deoxyguanosine by a monoclonal antibody N45. I: its application to ferric nitrilotriacetate-induced renal carcinogenesis model. Lab Invest 1997, 76:365-374

27. Shimoi K, Kasai H, Yokota N, Toyokuni S, Kinae N: Comparison between high-performance liquid chromatography and enzyme-linked immunosorbent assay for the determination of 8-hydroxy-2'-deoxyguanosine in human urine. Cancer Epidemiol Biomarkers Prev 2002/08/07 edition. 2002, I I:767-770.

28. Bacon BL, Pardue HL: Kinetic study of the Jaffe reaction for quantifying creatinine in serum: 2 . Evaluation of buffered reagent and comparison of different data-processing options. Clin Chem 1989, 35:360-363.

29. Liu G, Miller DP, Zhou W, Thurston SW, Fan R, Xu LL, Lynch TJ, Wain JC, Su L, Christiani DC: Differential association of the codon 72 p53 and GSTMI polymorphisms on histological subtype of non-small cell lung carcinoma. Cancer Res 200I, 61:8718-8722.

30. Tobin J: Estimation of Relationships for Limited Dependent Variables. Econometrica 1958, 26:24-36.

3I. Ding W, Hudson LG, Liu KJ: Inorganic arsenic compounds cause oxidative damage to DNA and protein by inducing ROS and RNS generation in human keratinocytes. Mol Cell Biochem 2005, 279: 105-112.

32. Dusinska M, Ficek A, Horska A, Raslova K, Petrovska H, Vallova B, Drlickova M, Wood SG, Stupakova A, Gasparovic J, Bobek P, Nagyova A, Kovacikova Z, Blazicek P, Liegebel U, Collins AR: Glutathione Stransferase polymorphisms influence the level of oxidative 
DNA damage and antioxidant protection in humans. Mutat Res 200I, 482:47-55.

33. Steinmaus C, Moore LE, Shipp M, Kalman D, Rey OA, Biggs ML, Hopenhayn C, Bates MN, Zheng S, Wiencke JK, Smith AH: Genetic polymorphisms in MTHFR 677 and I298, GSTMI and TI, and metabolism of arsenic. J Toxicol Environ Health A 2007/03/17 edition. 2007, 70:159-170.

34. Tseng $\mathrm{CH}$ : Arsenic methylation, urinary arsenic metabolites and human diseases: current perspective. J Environ Sci Health C Environ Carcinog Ecotoxicol Rev 2007/03/I7 edition. 2007, 25:I-22.

35. Sram RJ: Effect of glutathione S-transferase MI polymorphisms on biomarkers of exposure and effects. Environ Health Perspect 1998, 106 Suppl I:23I-239.

36. Bergamaschi E, De Palma G, Mozzoni P, Vanni S, Vettori MV, Broeckaert F, Bernard A, Mutti A: Polymorphism of quinone-metabolizing enzymes and susceptibility to ozone-induced acute effects. Am J Respir Crit Care Med 200I, 163:|426-143I.

37. Pilger A, Ivancsits S, Germadnik D, Rudiger HW: Urinary excretion of 8-hydroxy-2'-deoxyguanosine measured by high-performance liquid chromatography with electrochemical detection. J Chromatogr B Analyt Technol Biomed Life Sci 2002, 778:393-40I.

38. Pilger A, Germadnik D, Riedel K, Meger-Kossien I, Scherer G, Rudiger HW: Longitudinal study of urinary 8-hydroxy-2'-deoxyguanosine excretion in healthy adults. Free Radic Res 200I, 35:273-280.

39. Gamble MV, Liu $X$ : Urinary creatinine and arsenic metabolism - Environ Health Perspect 2005, I I 3:A442-3.

40. Rossman TG, Uddin AN, Burns FJ, Bosland MC: Arsenite is a cocarcinogen with solar ultraviolet radiation for mouse skin: an animal model for arsenic carcinogenesis. Toxicol Appl Pharmacol 200I, I76:64-7I.

Publish with Bio Med Central and every scientist can read your work free of charge

"BioMed Central will be the most significant development for disseminating the results of biomedical research in our lifetime. "

Sir Paul Nurse, Cancer Research UK

Your research papers will be:

- available free of charge to the entire biomedical community

- peer reviewed and published immediately upon acceptance

- cited in PubMed and archived on PubMed Central

- yours - you keep the copyright

Submit your manuscript here:

http://www.biomedcentral.com/info/publishing_adv.asp
BiolMedcentral 